\title{
Simulation Models for Three-phase Grid-connected PV Inverters Enabling Current Limitation under Unbalanced Faults
}

\author{
Le Hong Lam \\ Faculty of Electrical Engineering \\ The University of Danang-University \\ of Science and Technology \\ Da Nang, Vietnam \\ lhlam@dut.udn.vn
}

\author{
Tran Dai Hoang Phuc \\ Faculty of Electrical Engineering \\ The University of Danang-University \\ of Science and Technology \\ Da Nang, Vietnam \\ 105150107@sv.dut.edu.vn
}

\author{
Nguyen Huu Hieu \\ Faculty of Electrical Engineering \\ The University of Danang-University \\ of Science and Technology \\ Da Nang, Vietnam \\ nhhieu@dut.udn.vn
}

\begin{abstract}
Normally unbalanced grid voltage dips may lead to unbalanced non-sinusoidal current injections, DC-link voltage oscillations, and active and/or reactive power oscillations with twice the grid fundamental frequency in three-phase gridconnected Photovoltaic (PV) systems. Double grid frequency oscillations at the DC-link of the conventional two-stage PV inverters can further deteriorate the DC-link capacitor, which is one of the most important limiting components in the system. Proper control of these converters may efficiently address this problem. In such solutions, Current Reference Calculation (CRC) is one of the most important issues that should be coped with the reliable operation of grid-connected converters under unbalanced grid faults. Therefore, this paper proposes and simulates CRC methods and presents the results in order to improve the quality of the grid-connected PV system under unbalanced grid voltage fault.
\end{abstract}

Keywords-Photovoltaic (PV) systems; unbalance voltage; twostage converters; power oscillation; $D C$-link voltage oscillation

\section{INTRODUCTION}

With the fast increase of grid-connected PV generation [1, 2], PV systems should contribute to the grid stability by providing ancillary services, beyond the basic power delivery. The new grid requirements demand the grid-connected PV systems, single- or three-phase, to have the capability to operate in power factors other than unity. Also, based on the recently revised grid codes, PV inverters are preferred to stay connected during grid voltage faults [3-6]. When a fault happens, the converter has to detect the incident and respond quickly to the disturbance to mitigate the adverse effects on the inverter, the equipment connected to the grid, and the upstream system. Indeed, the revised grid codes require the PV systems to inject a certain amount of reactive power in case of low voltage fault $[7,8]$. These issues are now gaining more consideration in PV systems, as the power capacity of an individual PV system is also increasing. Detection of voltage sags, current limitation, current reference calculation [9], active and reactive power oscillation, and DC-link voltage oscillation are such important issues. Besides, they are the key issues to the proper operation of grid-connected PV converters under faults. Among them, CRC plays the most important role to satisfy the grid requirements, especially under unbalanced grid faults. In current researched methods, d-q methodology is commonly implemented under grid voltage faults $[3-6,10]$ although it is quite complex since it requires building blocks to convert the signals and calculate the frequency as the Phase Lock Loop (PLL), Dual Second Order Generalized Integrator Based Frequency-Locked Loop (DSOGI-FLL).

The aforementioned active power oscillation can have a negative impact on the reliable operation of the grid-connected PV converters. In two-stage PV converters, where a DC-DC converter operates as Maximum Power Point Tracking (MPPT) [11], it is common that a PI controller determines the active power reference. Thus, in case that the injected active power starts fluctuating, the PI controller cannot follow its sinusoidal variations because the PV power injected to the DC-link is constant. As a result, the DC-link voltage will fluctuate with the same frequency of the injected active power [12]. Notably, due to the high failure rates of the electrolytic capacitors of the two-stage PV converters, the system reliability is challenged. This is worsened by DC-link voltage ripples. In this paper there are two main contributions: (i) DC link ripples during unbalanced faults are reduced with proper control of DC-DC converter and (ii) the impact of the PV systems on the distribution grid is analyzed and a control strategy is proposed for the PV using calculation methods referenced in the static $\alpha$ $\beta$ reference frame to reduce the complexity of the control structure and more efficient instead of using moving $d-q$ reference frames. Moreover, the deprecating power of the main grid can be made by changing the power factor of wind generators [13-15]. This control strategy may offer a new solution to solve the voltage sag issue on a power system due to the PV plants connected to the grid by streaming their reactive power to the grid to enhance its power quality.

\section{SYSTEM OPERATION}

This section analyzes the inverter operation under normal and abnormal conditions for a three-wire three-phase PV system. The two-stage three-phase system shown in Figure 1 
includes a boost converter and a full-bridge inverter interconnected through the DC-link capacitor.

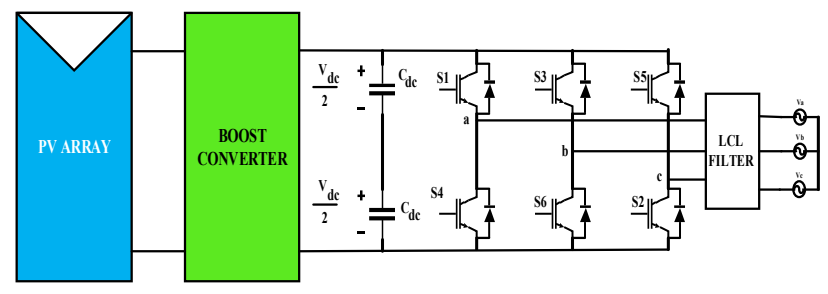

Fig. 1. Two-stage three-phase grid-connected PV system.

The formulation is performed in the Stationary Reference Frame (SRF). The conversion from the three-phase system into the $\mathrm{SRF}$ is as:

$$
v_{\alpha \beta}=\left[\begin{array}{l}
v_{\alpha} \\
v_{\beta}
\end{array}\right]=\sqrt{\frac{2}{3}}\left[\begin{array}{ccc}
1 & -\frac{1}{2} & -\frac{1}{2} \\
0 & \frac{\sqrt{3}}{2} & -\frac{\sqrt{3}}{2}
\end{array}\right]\left[\begin{array}{l}
v_{a} \\
v_{b} \\
v_{c}
\end{array}\right]
$$

where $v_{\alpha}, v_{\beta}$ are the voltages in the SRF from $v_{a}, v_{b}, v_{c}$. The apparent power $S$ is written as:

$$
S=v \cdot i^{*}=P+j Q
$$

Since under normal conditions the grid voltages and loads are balanced, there will not be any oscillatory components in the active and reactive components of the power and the injected current is completely sinusoidal. However, under unbalanced conditions, the NS components will appear in both current and voltage vectors. Thus, the apparent power is rewritten as:

$$
\begin{gathered}
S=v_{\alpha \beta} \cdot i_{\alpha \beta}{ }^{*}=\left(v_{\alpha \beta}^{+}+v_{\alpha \beta}^{-}\right) \cdot\left(i_{\alpha \beta}^{+}+i_{\alpha \beta}^{-}\right)^{*}=v_{\alpha \beta}^{+} \cdot i_{\alpha \beta}^{+}{ }^{*}+ \\
v_{\alpha \beta}^{+} \cdot i_{\alpha \beta}^{-}{ }^{*}+v_{\alpha \beta}^{-} \cdot i_{\alpha \beta}^{+}{ }^{*}+v_{\alpha \beta}^{-} \cdot i_{\alpha \beta}^{-}{ }^{*}
\end{gathered}
$$

in which $v_{\alpha \beta}^{+}, v_{\alpha \beta}^{-}$are derived from:

$$
\begin{aligned}
& v_{\alpha \beta}^{+}=\frac{1}{2}\left[\begin{array}{rr}
1 & -q \\
q & 1
\end{array}\right] v_{\alpha \beta} \\
& v_{\alpha \beta}^{-}=\frac{1}{2}\left[\begin{array}{lr}
1 & q \\
-q & 1
\end{array}\right] v_{\alpha \beta}
\end{aligned}
$$

where $q=e^{-j \pi / 2}$ is a $90^{\circ}$-lagging phase-shifting operator applied to the time domain [16]. Similarly, $i_{\alpha \beta}^{+}, i_{\alpha \beta}^{-}$are achieved following (4) and (5):

$$
\begin{aligned}
& i_{\alpha \beta}^{+}=\frac{1}{2}\left[\begin{array}{lr}
1 & -q \\
q & 1
\end{array}\right] i_{\alpha \beta} \\
& i_{\alpha \beta}^{-}=\frac{1}{2}\left[\begin{array}{lr}
1 & q \\
-q & 1
\end{array}\right] i_{\alpha \beta}
\end{aligned}
$$

In (3), there are four terms in the apparent power formulation.

$$
\begin{gathered}
v_{\alpha \beta}^{+} \cdot i_{\alpha \beta}^{+}{ }^{*}=\left(v_{\alpha}^{+}+j v_{\beta}^{+}\right) \cdot\left(i_{\alpha}^{+}+j i_{\beta}^{+}\right)^{*}=v_{\alpha}^{+} i_{\alpha}^{+}+v_{\beta}^{+} i_{\beta}^{+}+ \\
j\left(v_{\beta}^{+} i_{\alpha}^{+}-v_{\alpha}^{+} i_{\beta}^{+}\right)=P_{1}+j Q_{1} \\
v_{\alpha \beta}^{+} \cdot i_{\alpha \beta}^{-}=\left(v_{\alpha}^{+}+j v_{\beta}^{+}\right) \cdot\left(i_{\alpha}^{-}+j i_{\beta}^{-}\right)^{*}=v_{\alpha}^{+} i_{\alpha}^{-}+v_{\beta}^{+} i_{\beta}^{-}+ \\
j\left(v_{\beta}^{+} i_{\alpha}^{-}-v_{\alpha}^{+} i_{\beta}^{-}\right)=P_{2}+j Q_{2}
\end{gathered}
$$

$$
\begin{gathered}
v_{\alpha \beta}^{-} \cdot i_{\alpha \beta}^{+}{ }^{*}=\left(v_{\alpha}^{-}+j v_{\beta}^{-}\right) \cdot\left(i_{\alpha}^{+}+j i_{\beta}^{+}\right)^{*}=v_{\alpha}^{-} i_{\alpha}^{+}+v_{\beta}^{-} i_{\beta}^{+}+ \\
j\left(v_{\beta}^{-} i_{\alpha}^{+}-v_{\alpha}^{-} i_{\beta}^{+}\right)=P_{3}+j Q_{3} \\
v_{\alpha \beta}^{-} \cdot i_{\alpha \beta}^{-}{ }^{*}=\left(v_{\alpha}^{-}+j v_{\beta}^{-}\right) \cdot\left(i_{\alpha}^{-}+j i_{\beta}^{-}\right)^{*}=v_{\alpha}^{-} i_{\alpha}^{-}+v_{\beta}^{-} i_{\beta}^{-}+ \\
j\left(v_{\beta}^{-} i_{\alpha}^{-}-v_{\alpha}^{-} i_{\beta}^{-}\right)=P_{4}+j Q_{4}
\end{gathered}
$$

The constant and oscillating parts of the total active and reactive power are written as:

$$
\begin{gathered}
P=P_{0}+\tilde{P} \\
P_{0}=P_{1}+P_{4}=v_{\alpha}^{+} i_{\alpha}^{+}+v_{\beta}^{+} i_{\beta}^{+}+v_{\alpha}^{-} i_{\alpha}^{-}+v_{\beta}^{-} i_{\beta}^{-} \\
\tilde{P}=P_{2}+P_{3}=v_{\alpha}^{+} i_{\alpha}^{-}+v_{\beta}^{+} i_{\beta}^{-}+v_{\alpha}^{-} i_{\alpha}^{+}+v_{\beta}^{-} i_{\beta}^{+} \\
Q=Q_{0}+\tilde{Q} \\
Q_{0}=Q_{1}+Q_{4}=v_{\beta}^{+} i_{\alpha}^{+}-v_{\alpha}^{+} i_{\beta}^{+}+v_{\beta}^{-} i_{\alpha}^{-}-v_{\alpha}^{-} i_{\beta}^{-} \\
\tilde{Q}=Q_{2}+Q_{3}=v_{\beta}^{+} i_{\alpha}^{-}-v_{\alpha}^{+} i_{\beta}^{-}+v_{\beta}^{-} i_{\alpha}^{+}-v_{\alpha}^{-} i_{\beta}^{+}
\end{gathered}
$$

where $P$ and $Q$ are the total active and reactive power, and $P_{0}, Q_{0}, \tilde{P}, \tilde{Q}$ are the constant and oscillating parts in the active and reactive power.

Under balanced voltage sag faults, there is no NS in the voltages and currents, thus there are no oscillatory components in the active and reactive power. However, during unbalanced faults, the NS components appear in the voltages and currents. From (12) and (15), it is concluded that the active and reactive power have a constant part named $P_{0}$ and $Q_{0}$. Also, there are two oscillating parts in the active and reactive power, denoted as $\widetilde{P}$ and $\tilde{Q}$. Fundamentally, in the PV power systems, all the active power generated by the PV panels is delivered to the DC-link. This active power is continuously processed by the inverter and injected into the grid. If the active power generated by the inverter is less than the power injected to the DC link from the PV source, the DC link voltage will increase. Proper control is needed to synchronize the power flow from the PV source to the grid by regulating the DC link voltage. Accordingly, in the case that the injected active power has double grid frequency oscillations, the DC-link voltage will inevitably oscillate with the same frequency. Double grid frequency oscillations of the DC-link voltage have a negative impact on the life cycle of the capacitive DC-link.

\section{PROPOSED CONTROL STRATEGY}

In this section, a new control strategy to overcome the unbalance grid voltage based on the Current Reference Generation (CRG) is presented and a current limitation scheme is used to warranty the overcurrent issue.

\section{A. Current Reference Generation}

In order to eliminate active power oscillations, (14) has to be zero. In (14) and (17), $P_{0}$ and $Q_{0}$ are equal to the average active power ( $P_{\text {ref }}$ which is the output of the DC-link regulator) and reactive power $\left(Q_{r e f}\right.$ which is calculated during grid faults) references. These values are continuously calculated by the control algorithm. The control goal is to eliminate the oscillatory components from the active power, while allowing reactive power to oscillate with the double grid 
frequency. Hence, $\tilde{Q}$ is considered equal to $2\left(v_{\beta}^{+} i_{\alpha}^{-}-v_{\alpha}^{+} i_{\beta}^{-}\right)$. Accordingly, (17) is rewritten as:

$$
\begin{gathered}
\tilde{Q}=v_{\beta}^{+} i_{\alpha}^{-}-v_{\alpha}^{+} i_{\beta}^{-}+v_{\beta}^{-} i_{\alpha}^{+}-v_{\alpha}^{-} i_{\beta}^{+}=2\left(v_{\beta}^{+} i_{\alpha}^{-}-v_{\alpha}^{+} i_{\beta}^{-}\right) \\
v_{\beta}^{+} i_{\alpha}^{-}-v_{\alpha}^{+} i_{\beta}^{-}-v_{\beta}^{-} i_{\alpha}^{+}+v_{\alpha}^{-} i_{\beta}^{+}=0
\end{gathered}
$$

Furthermore, (13), (14), (16), (19) are written as:

$$
\left[\begin{array}{cccc}
v_{\alpha}^{+} & v_{\beta}^{+} & v_{\alpha}^{-} & v_{\beta}^{-} \\
v_{\alpha}^{-} & v_{\beta}^{-} & v_{\alpha}^{+} & v_{\beta}^{+} \\
v_{\beta}^{+}- & v_{\alpha}^{+} & v_{\beta}^{-} & -v_{\alpha}^{-} \\
-v_{\beta}^{-} & v_{\alpha}^{-} & v_{\beta}^{+} & -v_{\alpha}^{+}
\end{array}\right]\left[\begin{array}{c}
i_{\alpha}^{+} \\
i_{\beta}^{+} \\
i_{\alpha}^{-} \\
i_{\beta}^{-}
\end{array}\right]=\left[\begin{array}{c}
P_{r e f} \\
0 \\
Q_{r e f} \\
0
\end{array}\right]
$$

A formulation for generating sinusoidal currents to deliver a certain amount of active and reactive power $[3,17,18]$ is obtained as:

$$
\begin{gathered}
i_{\alpha}^{+}=\frac{v_{\alpha}^{+}}{V_{p}-V_{n}} P_{r e f}-\frac{v_{\alpha \perp}^{+}}{V_{p}+V_{n}} Q_{r e f} \\
i_{\alpha}^{-}=-\frac{v_{\alpha}}{v_{p}-V_{n}} P_{r e f}-\frac{v_{\alpha \perp}^{-}}{V_{p}+V_{n}} Q_{r e f} \\
i_{\beta}^{+}=\frac{v_{\beta}^{+}}{v_{p}-V_{n}} P_{r e f}-\frac{v_{\beta \perp}^{+}}{V_{p}+V_{n}} Q_{r e f} \\
i_{\beta}^{-}=-\frac{v_{\beta}^{-}}{V_{p}-V_{n}} P_{r e f}-\frac{v_{\beta}^{-}}{V_{p}+V_{n}} Q_{r e f} \\
{\left[\begin{array}{c}
v_{\alpha \perp} \\
v_{\beta \perp}
\end{array}\right]=\left[\begin{array}{ll}
0 & -1 \\
1 & 0
\end{array}\right]\left[\begin{array}{l}
v_{\alpha} \\
v_{\beta}
\end{array}\right]} \\
V_{p}=v_{\alpha}^{+2}+v_{\beta}^{+2} \\
V_{n}=v_{\alpha}^{-2}+v_{\beta}^{-2}
\end{gathered}
$$

where $v_{\alpha \perp}, v_{\beta \perp}$ are the orthogonal voltages of the SRF voltage vectors. The SRF currents are driven from the average value of the active and reactive power. These references determine the peak-peak value of the oscillations on the reactive power. Accordingly, a general formulation is obtained as:

$$
\begin{aligned}
& i_{\alpha P}=\frac{v_{\alpha}^{+}-v_{\alpha}^{-}}{\left(v_{\alpha}^{+2}+v_{\beta}^{+2}\right)+\left(v_{\alpha}^{-2}+v_{\beta}^{-2}\right)} P_{r e f} \\
& i_{\beta P}=\frac{v_{\beta}^{+}-v_{\beta}^{-}}{\left(v_{\alpha}^{+2}+v_{\beta}^{+2}\right)+\left(v_{\alpha}^{-2}+v_{\beta}^{-2}\right)} P_{r e f} \\
& i_{\alpha Q}=-\frac{v_{\alpha \perp}^{+}+v_{\alpha \perp}^{-}}{\left(v_{\alpha \perp}^{+}{ }^{2}+v_{\beta \perp}^{+}{ }^{2}\right)+\left(v_{\alpha \perp}^{-}{ }^{2}+v_{\beta \perp}^{-}{ }^{2}\right)} Q_{r e f} \\
& i_{\beta Q}=-\frac{v_{\beta \perp}^{+}+v_{\beta \perp}^{-}}{\left(v_{\alpha \perp}^{+}{ }^{2}+v_{\beta \perp}^{+}{ }^{2}\right)+\left(v_{\alpha \perp}^{-}{ }^{2}+v_{\beta \perp}^{-}{ }^{2}\right)} Q_{r e f}
\end{aligned}
$$

in which, $i_{\alpha P}, i_{\beta P}, i_{\alpha Q}, i_{\beta Q}$ are the active and reactive currents in the SRF.

\section{B. Current Limitation Scheme}

In order to prevent the overcurrent failure, a new efficient current limiting method is proposed. The rated power of the converter must be updated once a voltage sag is detected. This is called New Nominal Power (NNP). Normally, under voltage sag faults, the NNP value is less than the nominal power of the converter, which depends on the voltage sag depth. Therefore, NNP is achieved as:

$$
N N P=\frac{\sqrt{V_{p}}-\sqrt{V_{n}}}{V_{\text {base }}} S
$$

where $S$ is the apparent power or the nominal power of the power converter, $V_{\text {base }}$ is the base voltage, which is equal to the Root-Mean-Square (RMS) value of the line-line grid voltage. On the other hand, according to the voltage sag depth, the reactive power can be calculated as:

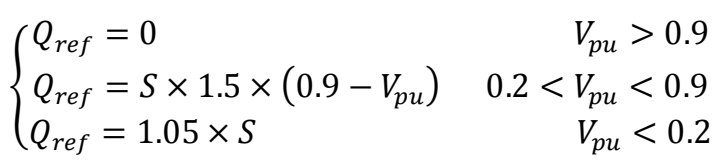

With $V_{p u}$ being calculated as:

$$
V_{p u}=\frac{\sqrt{v_{\alpha}^{2}+v_{\beta}^{2}}}{V_{\text {base }}}
$$

Given the $N N P$ and reactive power of $Q$, the maximum allowed active power $P_{\max }$ for the inverter to inject to the grid while avoiding overcurrent can be achieved as:

$$
P_{\max }=\sqrt{N N P^{2}-Q^{2}}
$$

For operation of the converter under very deep voltage sags, $N N P$ will have a low value, since $\sqrt{V_{p}}-\sqrt{V_{n}}$ becomes small. Therefore, under a deep voltage sag, the condition is:

$$
\text { If } Q>N N P \rightarrow Q=N N P \text { and } P_{\max }=0
$$

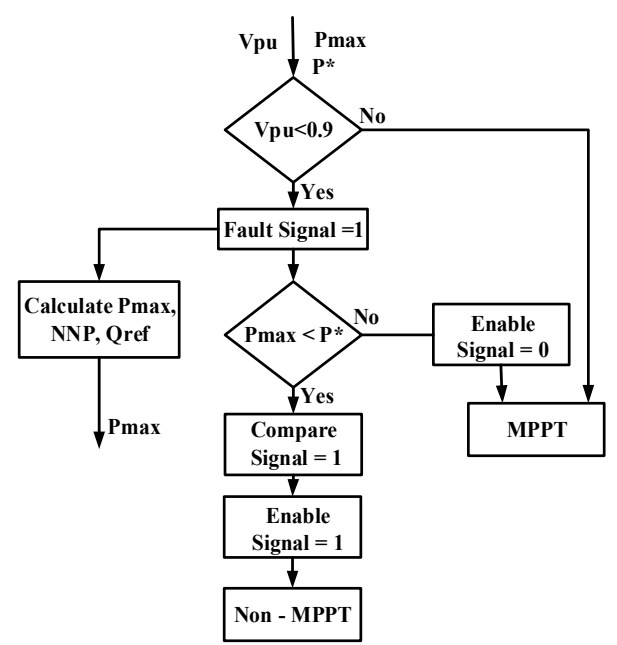

Fig. 2. Flowchart of the proposed control algorithm

The DC-DC converter operates as the MPPT-P\&O, the DC-DC converter should switch to the Non-MPPT mode in case a grid fault occurred and the inverter could not inject the maximum PV power. The flowchart in Figure 2 summarizes and clarifies the control system. If $V_{p u}<0.9$ the voltage sag detection block will generate a fault signal activating the $N N P, P_{\text {max }}, Q_{\text {ref }}$ calculator block. Then, for a comparison between $P_{\max }$ and $P^{*}$, a comparator signal will be generated There is an AND block, in which, if the comparator signal and 
fault signal are equal to 1, the DC-DC converter switches to the Non-MPPT. In this case, the fault signal is 1 , while the comparator signal remains zero. MPPT may continue working under abnormal operation when the fault exists in the grid.

\section{CONTROL STRUCTURE DESIGN}

A control structure was implemented in MATLAB/Simulink [19]. It should be noted that the proposed strategy control is mainly in Voltage Source Inverter (VSI) and current controller. Since, these modules play an important role in creating the reference current to balance voltage after faults.

\section{A. Voltage Source Inverter}

In connected grid mode, the VSI controller [20] power flow comes from the PV system to respond to the requirements of the grid, and control the voltage on the capacitor $C_{D C}$ of $\mathrm{DC}$ link. Active power is required from the grid reference given $P_{\text {ref }}$ from $V_{D C}$ voltage regulator. Meanwhile, reactive power $Q_{r e f}$ is calculated according to the current limit to stabilize the voltage on the AC bus. Figure 3 shows the schematic diagram of the $V_{D C}$ voltage control loop, the quantity to be controlled because it is proportional to the energy stored in the capacitor. DC voltage on the capacitor is stable thanks to the energy balance through (ignoring losses in VSI):

$$
P_{P V}=P_{D C}+P_{g}
$$

where $P_{P V}$ is the power from the PV, $P_{D C}$ is the power on the capacitor, and $P_{g}$ is the power inject to the grid.

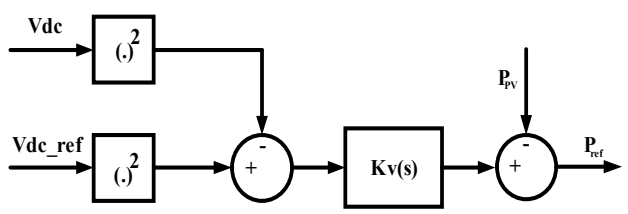

Fig. 3. Diagram control $V_{d c}$ voltage

When the voltage on the DC capacitor is stable, the value of the $P_{D C}$ is considered as zero:

$$
P_{P V}=P_{g}
$$

Equation (38) indicates that the controlling $P_{g}$ will be controlled through the $P_{g}$ to achieve the desired value. Then, the referenced currents $I_{\alpha r e f}$ and $I_{\beta r e f}$ are calculated through the reference power value from (39) and (40) and then they are taken to the current control.

$$
\begin{gathered}
i_{\alpha r e f}=\frac{v_{\alpha}^{+}-v_{\alpha}^{-}}{\left(v_{\alpha}^{+2}+v_{\beta}^{+2}\right)+\left(v_{\alpha}^{-2}+v_{\beta}^{-2}\right)} P_{r e f} \\
-\frac{v_{\alpha \perp}^{+}+v_{\alpha \perp}^{-}}{\left(v_{\alpha \perp}^{+}{ }^{2}+v_{\beta \perp}^{+}\right)+\left(v_{\alpha \perp}^{-}{ }^{2}+v_{\beta \perp}^{-}\right)} Q_{r e f} \\
i_{\beta r e f}=\frac{v_{\beta}^{+}-v_{\beta}^{-}}{\left(v_{\alpha}^{+2}+v_{\beta}^{+2}\right)+\left(v_{\alpha}^{-2}+v_{\beta}^{-2}\right)} P_{r e f} \\
-\frac{v_{\beta \perp}^{+}+v_{\beta \perp}^{-}}{\left({v_{\alpha \perp}^{+}}^{2}+v_{\beta \perp}^{+}{ }^{2}\right)+\left(v_{\alpha \perp}^{-}{ }^{2}+v_{\beta \perp}^{-}\right)} Q_{r e f}
\end{gathered}
$$

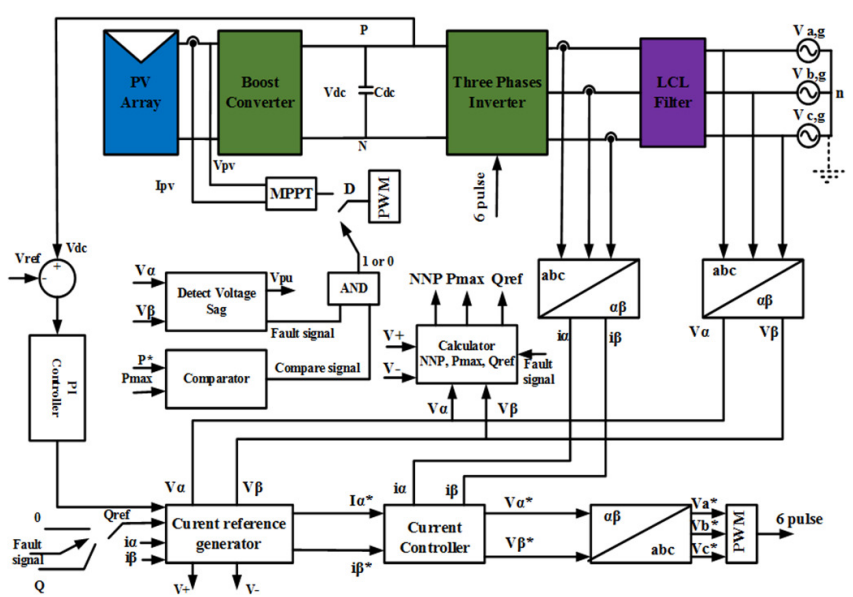

Fig. 4. Control structure of VSI [9] (the non MPPT mode is ignored)

\section{B. Current Controller}

The current controller in Figure 5 (current separator) has the aim to control and coordinate the active and reactive power. Its components involve $I_{\alpha r e f}$ and $I_{\beta r e f}$ to control active power and reactive power. After calculating the index modulations $m_{\alpha}, m_{\beta}$ from the current controller, a block converts from the SRF $\alpha-\beta$ to the Natural Reference Frame (NRF) $a b c$. A Clark transformation matrix will be used to convert $m_{\alpha}, m_{\beta}$ into $m_{a b c}$ index modulation. The control signals are included in the $m_{a b c}$ model of the VSI model to control power and achieve the desired value. The current control using with PI formulas are:

$$
\begin{aligned}
& V_{t \alpha}=V_{\alpha}+\left(I_{\alpha r e f}-I_{\alpha}\right)\left(K_{P}+\frac{K_{I}}{s}\right) \\
& V_{t \beta}=V_{\beta}+\left(I_{\beta r e f}-I_{\beta}\right)\left(K_{P}+\frac{K_{I}}{s}\right)
\end{aligned}
$$

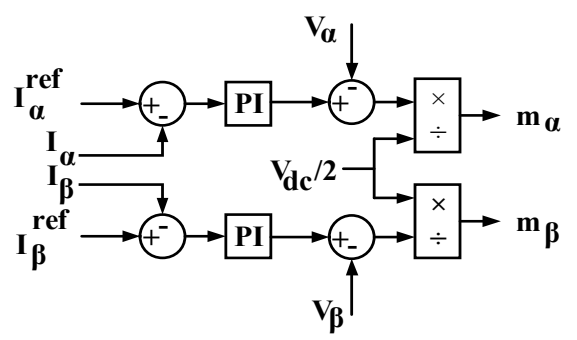

Fig. 5. Current controller

\section{Simulation RESUlts}

In order to verify the proposed control strategy, a simple PV system connected to the PCC is used as shown in Figure 6. In this simulation, a boost converter is connected to the PV and, as mentioned above, it is driven to track MPP. The output of the VSI is connected to the secondary side of distribution transformers (400V). The system is built on MATLAB/Simulink [19]. The main parameters of the system are presented in Table I. Here, the simulation scenario is that a fault occurs at $t=0.515 \mathrm{~s}$, thus voltages on phase $a$ and phase $b$ fall $50 \%$. The grid parameters of the simulation are shown in Figure 7 including the voltage of three phases without the 
proposed control strategy (Figure 7(a)), the injected current when applying the proposed control strategy to fix the unbalance voltage (Figure 7(b)), and the three phase voltage with the proposed control strategy (Figure 7(c)).

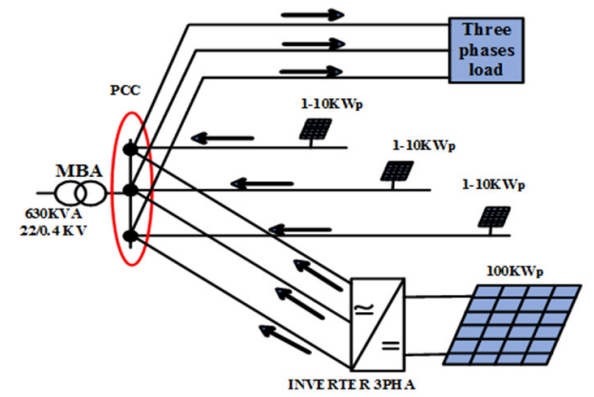

Fig. 6. Model simulation

TABLE I. SIMULATION PARAMETERS

\begin{tabular}{|c|c|c|}
\hline \multirow{2}{*}{ Description } & \multicolumn{2}{|c|}{ Simulation parameters } \\
\cline { 2 - 3 } & Symbol & Value \\
\hline Maximum power of PV systems & $P_{p v}$ & $100 \mathrm{kWp}$ \\
\hline Grid line-Line voltage (RMS) & $V_{g}$ & $381 \mathrm{~V}$ \\
\hline DC-link voltage & $V_{d c}$ & $500 \mathrm{~V}$ \\
\hline Resistance of the AC filter of the VSI & $R_{f}$ & $0.75 \mathrm{~m} \Omega$ \\
\hline Inductance of the AC filter of the VSI & $L_{f}$ & $100 \mu \mathrm{H}$ \\
\hline Capacitor of the DC-link & $C_{d c}$ & $0.2 \mathrm{~F}$ \\
\hline Grid frequency & $f$ & $50 \mathrm{~Hz}$ \\
\hline \multicolumn{2}{|c|}{} \\
\hline
\end{tabular}

(a)

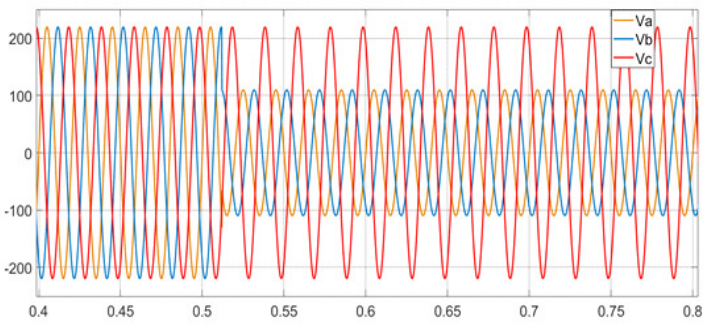

(b)
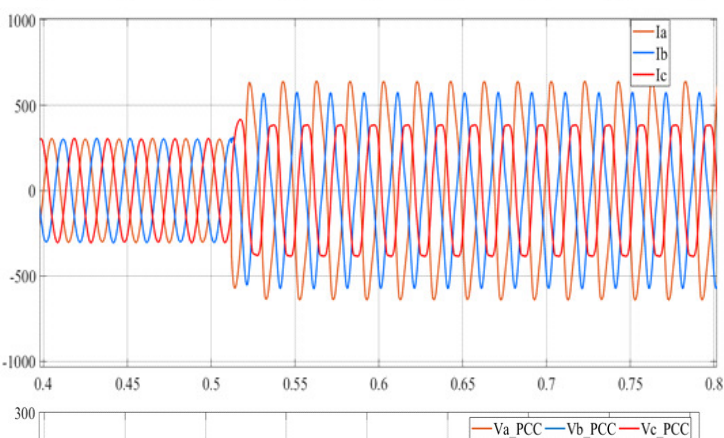

(c)

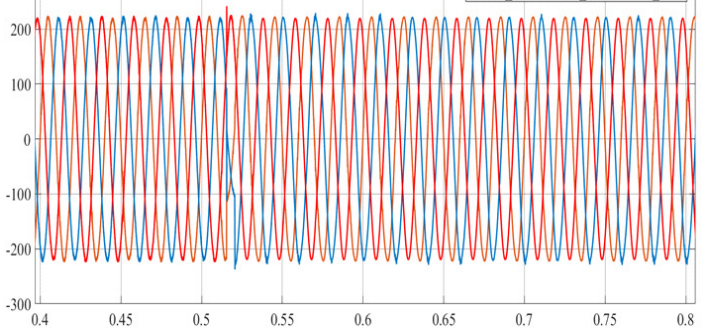

Fig. 7. Grid parameters: a) PCC voltage before injecting reference current, b) PV system current injected to the grid under fault occurrence, c) PCC voltage after injecting reference current
When fault occurred, $V_{p u}$ dropped to 0.69 , and the system switched to operate under fault mode (Figure 4) since $V_{p u}<0.9$ at the time of the error. $V_{a}$ and $V_{b}$ were halved, the current of phase a and phase $\mathrm{b}$ increased but phase $\mathrm{c}$ remained stable. After current reference was injected at $t=0.515 \mathrm{~s}$, the voltage at the connection point (Point of Common CouplingPCC) restored the three-phase loads to the rated value as shown in Figure $7(\mathrm{c})$. Moreover, the proposed control strategy guarantees that the oscillation of the DC-link voltage is acceptable. Figure 8 shows the output data of the system including the active power and reactive power in Figure 8(a) and $8(\mathrm{~b})$, the active power reference of the inverter in Figure $8(\mathrm{c})$, and the oscillation of the voltage of DC-link in Figure 8(d). Because the system is operating in sheltered MPPT P\&O algorithm [11], the output active power of the system remains at the maximum value shown in Figure 8(a). When unbalanced voltage sag was detected, the system responded and corrected the error immediately releasing reactive power to the grid in order to fix unbalances (Figure 8(b)).

(a)
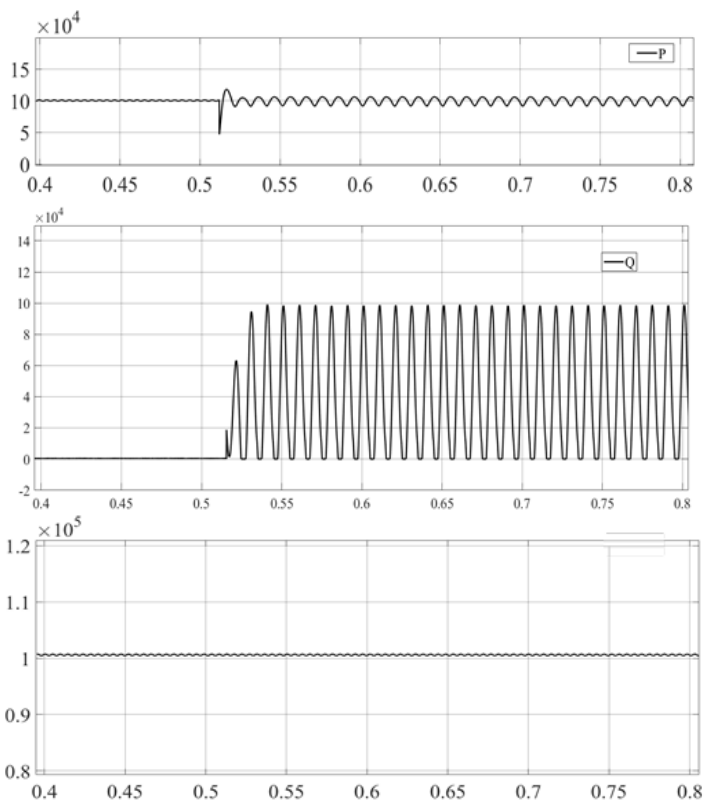

(d)

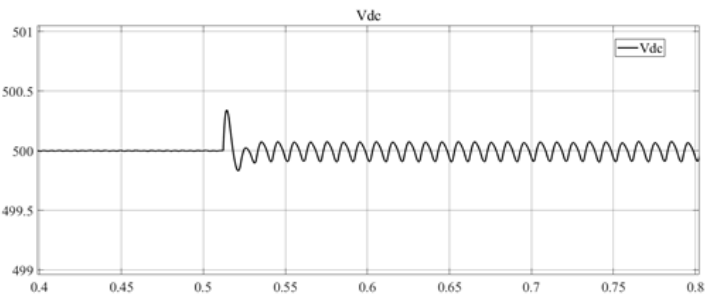

Fig. 8. The power output parameters of the system: a) active power injected to the grid, b) reactive power injected to the grid, c) active power reference, d) voltage of DC - link

At $t=0.515 \mathrm{~s}$, active power reference is required to be injected to the grid depending on the capacity of PV controlled under P\&O algorithm. As shown in Figure 8(c), the DC-link voltage started to oscillate with the frequency of active power but maintained stability in 500V (Figure 8(d)). Under fault 
conditions, the PV systems were injecting $100 \mathrm{kWp}$ active power to the grid and reactive power is $59.3 \mathrm{kVAR}$.

\section{CONCLUSION}

The simulation results of the proposed strategy control of the current reference generation show that the proposed control strategy has been successful in detecting voltage sags and in properly responding to fault conditions of a $100 \mathrm{kWp}$ gridconnected PV system. The proposed control strategy removes the active power and voltage oscillations in the DC-link. Therefore, the voltage at the PCC is restored to the nominal value ensuring power quality.

\section{ACKNOWLEDGMENT}

This work is funded by the Ministry of Education and Training, Vietnam, code: B2019-DNA-13.

\section{REFERENCES}

[1] J. Hossain, A. Mahmud, Renewable energy integration: Challenges and solutions, Springer Science \& Business Media, 2014

[2] M. A. Aman, S. Ahmad, B. Noor, F. W. Karam, "Mitigating the adverse impact of un-deterministic distributed generation on a distribution system considering voltage profile", Engineering, Technology \& Applied Science Research, Vol. 8, No. 3, pp. 2998--3003, 2018

[3] A. Junyent-Ferre, O. Gomis-Bellmunt, T. C. Green, D. E. Soto-Sanchez, "Current control reference calculation issues for the operation of renewable source grid interface VSCs under unbalanced voltage sags", IEEE Transactions on Power Electronics, Vol. 26, No. 12, pp. 37443753, 2011

[4] P. A. N. Garcia, J. L. R. Pereira, S. Carneiro, Jr., V. M. da Costa, N Martins, "Three-phase power flow calculations using the current Injection", IEEE Transactions on Power Systems, Vol. 15, No. 2, pp. $508-514,2000$

[5] T. Khatib, W. Elmenreich, Modeling of photovoltaic systems using Matlab: Simplified green codes, Wiley, 2016

[6] A. E. Alvarez, A. Junyent-Ferre, O. Gomis-Bellmunt, "Active and reactive power control of grid connected distributed generation systems", in: Modeling and control of sustainable power systems. Green energy and technology, pp. 47-81, Springer, 2012

[7] A. von Jouanne, B. Banerjee, "Assessment of voltage unbalance”, IEEE Transactions on Power Delivery, Vol. 16, No. 4, pp. 782-790, 2001

[8] F. Shahnia, A. Ghosh, G. Ledwich, F. Zare, "Voltage unbalance reduction in low voltage distribution networks with rooftop PVs", 20th Australasian Universities Power Engineering Conference, Christchurch, New Zealand, December 5-8, 2010

[9] E. Afshari, G. R. Moradi, R. Rahimi, B. Farhangi, Y. Yang, F. Blaabjerg, S. Farhangi, "Control strategy for three-phase grid-connected PV inverters enabling current limitation under unbalanced faults", IEEE Transactions on Industrial Electronics, Vol. 64, No. 11, pp. 8908-8918, 2017

[10] Z. Yan, Y. Xue, X. P. Zhang, "PI parameters determination in dq decoupling control of VSC terminals", 13th IET International Conference on $\mathrm{AC}$ and DC Power Transmission, Manchester, UK, February 14-16, 2017

[11] N V. Tan, D. M. Quan, T. A. Tuan, P. V. Kien, L. H. Lam, H. H. Long, "So sanh cac thuat toan bat diem cong suat cuc dai bang phuơng phap mo phong va thuc nghiem", Tap chi Khoa hoc va Cong nghe, Vol. 2, No. 11, pp. 64-68, 2018 (in Vietnamese)

[12] H. Wang, F. Blaabjerg, "Reliability of capacitors for DC-link applications in power electronic converters: An overview", IEEE Transactions on Industry Applications, Vol. 50, No. 5, pp. 3569-3578, 2014

[13] N. H. Hieu, L. H. Lam, "Using double fed induction generator to enhance voltage stability and solving economic issue", IEEE
International Conference on Sustainable Energy Technologies, Hanoi, Vietnam, November 14-16, 2016

[14] N. H. Hieu, L. H. Lam, C. T. Luu, T. Q. Tuan, "Effects of DFIG wind power generation on Vietnam power system operation", IEEE Eindhoven PowerTech, Eindhoven, Netherlands, June 29-July 2, 2015

[15] A. B. Lajimi, S. A. Gholamian, M. Shahabi, "Modeling and control of a DFIG-based wind turbine during a grid voltage drop", Engineering, Technology \& Applied Science Research, Vol. 1, No. 5, pp. 121-125, 2011

[16] P. Rodriguez, R. Teodorescu, I. Candela, A. V. Timbus, M. Liserre, F. Blaabjerg, "New positive-sequence voltage detector for grid synchronization of power converters under faulty grid conditions", 37th IEEE Power Electronics Specialists Conference, Jeju, South Korea, June 18-22, 2006

[17] R. Teodorescu, M. Liserre, P. Rodriguez, Grid converters for photovoltaic and wind power systems, Wiley, 2011

[18] S. Chattopadhyay, M. Mitra, S. Sengupta, "Clarke and Park transform", in: Electric power quality. Power systems, Springer, 2011

[19] Mathworks, "Simulation and model-dased design", available at: https://www.mathworks.com/products/simulink.html.

[20] A Yazdani, R Iravani, Voltage-sourced converters in power systems, Wiley, 2010 